\title{
A More In-depth Evaluation of Impedance-pH Could Assist in Distinguishing Reflux-related From Reflux-unrelated Heartburn
}

TO THE EDITOR: We read with interest the study by Penagini et al, ${ }^{1}$ who investigated 50 refractory patients with a diagnosis of functional heartburn $(\mathrm{FH})$ according to Rome III criteria in the first 24 hours of wireless $\mathrm{pH}$ monitoring. They described that $15 / 50$ patients had a pathological acid exposure time (AET) after the first day of monitoring, which changed their diagnosis from FH to non-erosive reflux disease (NERD). The authors concluded that more prolonged $\mathrm{pH}$-recording period was able to increase NERD diagnosis in patients wrongly classified as $\mathrm{FH}$ patients.

We congratulate the authors with their study that underlined one of the main limitation of the 24-hour tests such as impedance $\mathrm{pH}$ monitoring, that is the day-to-day variability. However, we would like to stress that with the recent novelties regarding the potential application of 24-hours impedance-pH monitoring, this limitation could be overcome without the need of additional tests, but with a more in depth analysis of impedance tracings. Indeed, impedance-pH has different advantages compared to $\mathrm{pH}$-metry only. First, impedance-pH can recognize patients in whom symptoms are related to non-acid reflux events. ${ }^{2,3}$ In keeping, providing data on all type of reflux and their association with symptoms, impedance-pH has shown the ability to rule out reflux as the main cause of esophageal symptoms and to refine the current definition of functional heartburn. ${ }^{3}$ Nevertheless, the limitation related to the day-to-day variability in AET and symptom perception still persists, although reduced, and so far the test may be inaccurate. ${ }^{4}$ To confirm, in 2 different studies a lack of correlation between the 24-hour monitoring and response to proton pump inhibitor therapy has been observed. ${ }^{5,6}$

However, recently, novel impedance parameters, manually calculated, evaluating esophageal chemical clearance, the post-reflux swallow-induced peristaltic wave (PSPW) index, and mucosal integrity, the baseline impedance, have been proposed. ${ }^{7-9}$ The PSPW index is suitable for valuation off as well as on proton pump inhibitor therapy: lower values have been found in erosive than in NERD, in both significantly lower than in $\mathrm{FH}^{7}$ Baseline impedance values were found strictly associated with epithelial structural abnormalities and are inversely correlated with AET. ${ }^{10}$ These impedance features provided promising results in distinguishing patients with reflux disease from those without and seem to be not affected by day-to-day variability and further limitations associated to AET or symptoms perception.

In line with these findings, we suggest that a more in-depth evaluation of multichannel intraluminal impedance-pH could assist in distinguishing reflux-related from reflux-unrelated heartburn. However, further outcome studies are mandatory to confirm their relevance in gastroesophageal reflux disease management.

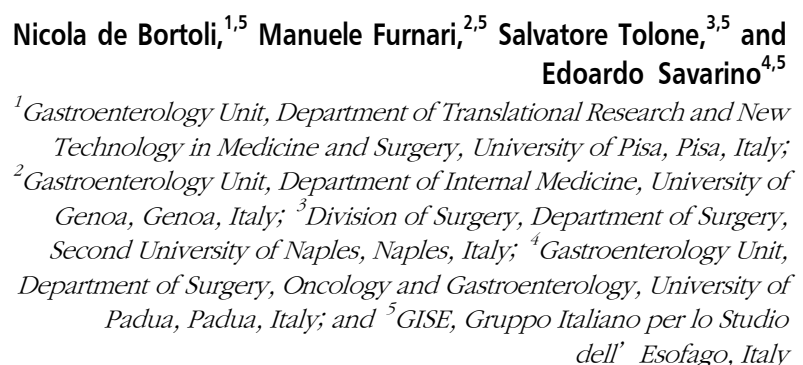

1. Penagini R, Sweis R, Mauro A, Domingues G, Vales A, Sifrim D. Inconsistency in the diagnosis of functional heartburn: usefulness of prolonged wireless $\mathrm{pH}$ monitoring in patients with proton pump inhibitor refractory gastroesophageal reflux disease. J Neurogastroenterol Motil 2015;21:265-272.

2. Savarino E, Zentilin $\mathrm{P}$, Tutuian $\mathrm{R}$, et al. The role of nonacid reflux in NERD: lessons learned from impedance-pH monitoring in 150 patients off therapy. Am J Gastroenterol 2008;103:2685-2693.

3. Savarino E, Zentilin P, Mastracci L, et al. Microscopic esophagitis distinguishes patients with non-erosive reflux disease from those with functional heartburn. J Gastroenterol 2013;48:473-482.

4. Slaughter JC, Goutte M, Rymer JA, et al. Caution about over- 
interpretation of symptom indexes in reflux monitoring for refractory gastroesophageal reflux disease. Clin Gastroenterol Hepatol 2011;9: 868-874.

5. de Bortoli N, Martinucci I, Savarino E, et al. Proton pump inhibitor responders who are not confirmed as GERD patients with impedance and $\mathrm{pH}$ monitoring: who are they? Neurogastroenterol Motil 2014;26:28-35.

6. Savarino E, Marabotto E, Zentilin P, et al. The added value of impedance-pH monitoring to Rome III criteria in distinguishing functional heartburn from non-erosive reflux disease. Dig Liver Dis 2011;43:542-547.

7. Frazzoni M, Manta R, Mirante VG, Conigliaro R, Frazzoni L, Melotti G. Esophageal chemical clearance is impaired in gastroesophageal reflux disease--a 24-h impedance-pH monitoring assessment. Neurogastroenterol Motil 2013;25:399-406, e295.
8. Martinucci I, de Bortoli N, Savarino E, et al. Esophageal baseline impedance levels in patients with pathophysiological characteristics of functional heartburn. Neurogastroenterol Motil 2014;26:546-555.

9. de Bortoli N, Martinucci I, Savarino E, et al. Association between baseline impedance values and response proton pump inhibitorsin patients with heartburn. Clin Gastroenterol Hepatol 2015;13:10821088, e1.

10. Zhong C, Duan L, Wang K, et al. Esophageal intraluminal baseline impedance is associated with severity of acid reflux and epithelial structural abnormalities in patients with gastroesophageal reflux disease. J Gastroenterol 2013;48:601-610.

Conflicts of interest: None. 